\title{
Soil quality under different land uses in hot semi- arid agro-ecological region of India
}

DENIS M.K. AMARA AND PARAMESHGOUDA L. PATIL

Received : 01.09.2014; Revised : 15.09.2014; Accepted : 01.10.2014

MEMBERS OF RESEARCH FORUM:
Corresponding author :
DENIS M.K. AMARA, Department of
Soil Science, School of Agriculture,
Njala University, Njala Campus,
MOYAMBA(SIERRA LEONE) WEST
AFRICA
Email: denismken@ yahoo.com

Co-authors :

PARAMESHGOUDA L. PATIL, Department of Soil Science and Agricultural Chemistry, College of Agriculture, University of Agricultural Sciences, DHARWAD (KARNATAKA) INDIA

\section{Summary}

A study was undertaken to identify important soil quality indicators and develop soil quality index for different land uses in Singhanhalli-Bogur micro watershed of northern transition zone of Karnataka. Soil samples were collected and analyzed following standard analytical procedures. Principal component analysis (PCA) was used to select a minimum data set that best represent soil functions of the study area. Five soil quality indicators, namely clay, silt, porosity, exchangeable $\mathrm{Mg}$ and organic carbon were identified as the best soil attributes that represent soil functions. A high degree of correlation was observed between the soil attributes. The soil quality varied from low to high. A major portion of the study area was under medium and high soil quality but larger portion was under medium soil quality. Soil quality under forest was higher than open scrub, plantation and agriculture. The application of organic and inorganic fertilizers as well as appropriate land uses such as forestry was recommended in order to improve the soil quality of the study area.

Key words : Singhanhalli-Bogur, Soil quality, Principal component analysis, Land use, Matrix correlation

How to cite this article : Amara, Denis M.K. and Patil, Parameshgouda L. (2014). Soil quality under different land uses in hot semi-arid agro-ecological region of India. Asian J. Soil Sci., 9(2) : 158-164. 